\title{
CrimRxiv
}

\section{Terrorism, Criminal Law and Politics: The Decline of the Political Offence Exception to Extradition}

\section{Jansson Julia}

Published on: Aug 12, 2019

DOI: $10.21428 / c b 6 a b 371 . c 64 a 01 c 9$

License: Creative Commons Attribution 4.0 International License (CC-BY 4.0). 
